\title{
Pengenalan Huruf Hijaiyyah melalui Media Kartu Gambar pada Anak
}

\author{
Nurhayati $^{\llbracket}$, Andi Agusniatih1, Amrullah1, I Putu Suwika1 \\ Pendidikan Guru Pendidikan Anak Usia Dini, Universitas Tadulako, Indonesia ${ }^{(1)}$ \\ DOI: $10.31004 /$ obsesi.v6i3.1850
}

\begin{abstract}
Abstrak
Nilai agama sangat penting untuk dikembangkan pada anak usia dini karena hal tersebut merupakan salah satu aspek yang harus dikembangkan pada anak usia dini sehingga nilai agama terkait mengenal huruf Hijaiyyah dikembangkan melalui media kartu gambar. Penelitian ini bertujuan untuk mengembangkan nilai agama anak melalui media kartu gambar. Metode Penelitian dilakukan menggunakan pendekatan reaserch and development. Teknik yang digunakan untuk mengumpulkan data dalam penelitian ini adalah observasi dan wawancara. Hasil observasi dianalisis dengan menggunakan analisis uji $\mathrm{t}$ test dan manova. Hasilnya diperoleh nilai rata-rata pengamatan dari 15 anak yang menjadi sampel penelitian pretest 23,20 sedangkan posttet diperoleh nilai rata-rata 35,867. Selanjutnya dilakukan uji lapangan menggunakan kelas kontrol dan kelas ekspreimen diperoleh nilai rata-rata, kelas eksperimen diperoleh nilai rata-rata pretest 34.10 sedangkan posttest 40.50 , kelas kontrol memperoleh nilai rata-rata pretest 29.14 sedangkan posttest 37.00. Kemudian dilakukan uji manova hotellings trace diperoleh nilai kurang dari $(<0,05)$ sehingga dapat disimpulkan bahwa media gambar untuk pengenalan huruf hijaiyyah dapat mengembangkan nilai agama anak.
\end{abstract}

Kata Kunci: anak usia dini; media kartu gambar; pengenalan huruf hijaiyyah

\begin{abstract}
Religious values are very important to be developed in early childhood because this is one aspect that must be developed in early childhood so that religious values related to recognizing Hijaiyyah letters are developed through the media of picture cards. This study aims to develop children's religious values through the media of picture cards. Methods The research was conducted using a research and development approach. The technique used to collect data in this research is observation and interviews. The results of the observations were analyzed using $t$ test and manova analysis. The results obtained the average value of observations of 15 children who were the sample of the pretest study was 23.20 while the posttest obtained an average value of 35.867 . Furthermore, field tests were carried out using the control class and the experimental class, the average value was obtained, the experimental class obtained the pretest average value of 34.10 while the posttest was 40.50 , the control class obtained the pretest average value of 29.14 while the posttest was 37.00. Then the manova hotellings trace test was carried out with a value of less than $(<0.05)$ so it can be concluded that the image media for introducing hijaiyyah letters can develop children's religious values.
\end{abstract}

Keywords: early childhood; Image cards Media, Hijaiyyah Letter Recognition

Copyright (c) 2021 Nurhayati, et al.

$\triangle$ Corresponding author :

Email Address : andiagusniatih@gmail.com (Palu, Indoenesia)

Received 8 September 2021, Accepted 26 December 2021 tahun, Published 30 December 2021 


\section{PENDAHULUAN}

Anak usia dini adalah sosok individu kecil yang tengah tumbuh dan berkembang baik secara fisik maupun psikologisnya. Oleh karena itu untuk membantu perkembangan dan pertumbuhannya dibutuhkan sentuhan pendidikan yaitu pendidikan anak usia dini. Pendidikan anak usia dini pada hakikatnya adalah pendidikan yang diselenggarakan dengan tujuan untuk memfasilitasi pertumbuhan dan perkembangan anak secara menyeluruh atau menekankan pada perkembangan seluruh aspek kepribadian anak (Wang et al., 2015). Pendidikan anak Usia dini merupakan salah satu bentuk penyelenggaraan pendidikan yang menitiberatkan pada peletakkan dasar kearah pertumbuhan dan perkembangan fisik, kecerdasan, emosi, agama moral, bahasa, sesuai dengan keunikan dan tahap-tahap perkembangan yang dilewati oleh anak usia dini (Hakim \& Dalli, 2016). Oleh karena itu Lembaga pendidikan anak usia dini menyelenggarakan dan menyediakan berbagai kegiatan pembelajaran yang dapat mengembangkan aspek-aspek perkembangan anak tersebut, salah satunya perkembangan yang harus dan wajib dikembangkan dan di rangsang adalah nilai agama anak (Anggraini \& Syafril, 2018). Mengembangkan nilai agama pada anak sangat penting dikembangkan sejak dini, agar anak dapat mengetahui mengenal huruf hijaiyyah, sikap yang baik dan buruk, benar salah, jujur, sabar, ikhlas, disiplin, bertanggung jawab, bersyukur, menghormati yang lebih tua, menyayangi yang lebih muda, sopan santun, serta dapat mengenal sifat- sifat Allah. Dengan dasar pengetahuan akhlak yang baik, maka anak akan patuh terhadap peraturan sekolah, agama, negara untuk masa depannya. Dengan diberikannya landasan pendidikan agama, moral kepada anak PAUD, maka anak PAUD belajar membedakan perilaku yang baik dan buruk, benar dan salah, serta terbiasa menjalankan ajaran agama sesuai dengan tingkat pertumbuhan dan perkembangannya (Ardiansari \& Dimyati, 2021). Inawati (2017) menyimpulkan pendidikan anak usia ini merupakan salah satu upaya pelestarian moralitas yang sangat berpengaruh dalam kehidupan suatu bangsa. Pendidikan anak usia dini mencakup pembinaan atau pengembangan terhadap nilai-nilai agama yang berperan dalam memperbaiki kehidupan bangsa.

Pendidikan nilai agama pada anak usia dini merupakan dasar atau pondasi yang kokoh yang harus dikembangkan pada anak usia dini (Ananda, 2017). Apabila nilai agama tidak dikembangkan sejak usia dini, dalam hal mengaji atau mengenalkan huruf huruf hijaiyah sejak dini akan mempengaruhi kehidupan anak kedepannya. Anak tidak akan bisa membaca Al-Qur'an atau mengaji karena tidak dikenalkan sejak dini. Nilai agama pada anak usia dini dikembangkan dengan pembiasaan sehari-hari dari guru maupun orangtua. Selain itu pengenalan dalam mengembangkan nilai agama anak bisa menggunakan metode atau media.

Penelitian terdahulu dilakukan oleh Zahrotun tentang pengenalan huruf hijaiyah yaitu menggunakan teknologi informasi yang dapat mencakup aspek-aspek perkembangan anak maka diperlukan sebuah media pembelajaran berbasis komputer. Di mana media pembelajaran tersebut dapat meningkatkan kreativitas dan efektifitas anak dalam belajar. Dalam pengenalan huruf hijaiyah ini anak dapat memilih salah satu huruf hijaiyah kemudian system akan menampilkan dalam tampilan yang lebih besar diikuti dengan suara lafal huruf hijayah tersebut. Ini berlaku untuk semua huruf hijaiyah. Sedangkan jika memilih tebaktebakan akan masuk pada permainan menebak huruf hijaiyah (Zahrotun, 2015). Sedangkan penelitian yang dilakukan oleh Hasanuddin (2017) mengatakan guru sebaiknya membuat perencanaan pembelajaran yang lebih baik dengan mempersiapkan rencana pembelajaran yang sistematis sehingga mudah dalam proses belajar berlangsung dan media yang diperlukan. Anak belajar dengan suasana yang menyenangkan, jika anak senang, nyaman, fokus sangat mudah bagi anak menerima informasi yang guru sampaikan. pendidik harus banyak mempunyai ide-ide baru sehingga anak dapat, dan membuat anak menarik belajar sehingga anak mendapatkan kesempatan bermain yang cukup. Mengingat penggunaan media kartu huruf hijaiyah dapat melejitkan kecerdasan spiritual anak sehingga berguna 
untuk anak dalam menerapkan pada kehidupan sehari-hari, maka para pihak terkait atau lembaga PAUD untuk mengimplementasikan penggunaan media kartu huruf hijaiyah (Haanuddin, 2017).

Hasil pengamatan saat observasi awal selama satu minggu wawancara dengan guru TK, dari 25 anak yang diamati, sekitar $75 \%$ anak belum berkembang sesuai yang diharapkan. Dimana masih banyak anak yang kurang mengenal, menyebutkan dan membedakan huruf hijaiyyah. Hal ini disebabkan karena kurangnya kegiatan belajar yang menuntut anak untuk mengenalkan huruf hijaiyyah, terbiasa menjalankan ajaran agama sesuai dengan tingkat pertumbuhan dan perkembangannya. Metode dan media yang digunakan guru kurang bervariasi, masih banyak guru kurang kreatif dalam mengajar, masih menggunakan metode konvensional sehingga terlihat sangat membosankan bagi anak, kurangnya guru memiliki media pembelajaran yang digunakan dalam proses pembelajaran daring misalnya laptop untuk meningkatkan pemahaman anak dalam pengenalan huruf hijaiyyah dalam pengenalan huruf hijaiyyah, jaringan yang bermasalah,kurangnya memberikan media yang menarik supaya anak tidak bosan, anak mempunyai orang tua yang sibuk dengan aktifitasnya sesuai dengan profesinya misalnya dikantoran, dokter, polisi, pedagang, petani, tukang kayu/batu, pegawai rumah sakit dan wiraswasta, bahkan tidak mempunyai waktu yang cukup untuk mendampingi anak dalam mengikuti pembelajaran daring, ada juga orang tua yang kurang faham mengaplikasikan computer,atau tidak mempunyai computer untuk digunakan pembelajaran daring. Sehingga pada umumnya anak usia dini tidak aktif mengikuti pembelajaran daring terutama dalam pengenalan huruf hijaiyyah, orang tua mengharapkan pembimbingan dari guru, dan ikut kegiatan taman pengajian Al-Quran akan tetapi karena suasana covid 19 termasuk TPA juga ditutup. Hasil wawancara dengan 7 orang guru kelas, 2 orang menyatakan pernah menggunakan menayangkan gerak dan lagu dan tarian, kemudian 5 orang menyatakan bahwa media pembelajaran kurang diterapkan dalam kegiatan pembelajaran karena keterbatasan fasilitas disediakan sekolah, guru tidak mau repot menyiapkan segala sesuatunya, menampilkan media kartu gambar, sehingga metode dan media ini jarang digunakan disekolah, padahal penerapan metode dan media dapat memberikan pengalaman belajar pada anak usia dini dengan menunjukkan, gambar, video, kaset atau media lainnya untuk mengenalkan huruf hijaiyyah dalam pembelajaran untuk meningkatkan nilai-nilai agama anak.

Pembelajaran pada anak TK khususnya mengenal huruf hijaiyah di mulai dari kemampuan anak dalam mengenal huruf-huruf hijaiyyah, berbeda dengan belajar menggambar dan mewarnai, belajar mengenal huruf hijaiyyah dan membutuhkan daya ingat yang kuat, karena itu di perlukan media kartu gambar huruf hijaiyyah dan metode yang tepat agar anak mudah mengingat setiap huruf hijaiyyah. Oleh karena itu, dari uraian tersebut menjelaskan perkembangan nilai agama anak masih perlu ditingkatkan, perlu adanya solusi menangani masalah tersebut. Salah satunya menggunakan media kartu gambar. Media kartu gambar dijadikan solusi untuk meningkatkan perkembangan nilai agama pada anak. Untuk itu terkait, dengan tujuan Dirjen PAUD tentang pengembangan enam aspek perkembangan anak usia dini, pengembangan nilai agama anak tentang pengenalan huruf hijaiyyah sebaiknya ditanamkan sejak usia dini.

Huruf hijaiyyah adalah kumpulan huruf arab yang berjumlah 29 huruf. Huruf- huruf inilah yang terpakai dalam aL-Qur'an dan dikenal pada masa sekarang. Kata huruf berasal dari bahasa arab harf atau huruuf. Huruf arab juga disebut huruf hijaiyyah. Kata hijaiyyah berasal dari kata kerja hajja yang artinya mengeja, menghitung huruf, membaca huruf demi huruf. Huruf hijaiyyah di sebut pula huruf tahjiyyah. Huruf hijaiyyah di sebut juga alfabet arab karna mempunyai aturan yang mana di lafazkan dari huruf hijaiyya dimulai dari alif dan berakhir pada huruf ya. Oleh karena itu, Huruf Hijaiyyah di lafazkan setiap membaca alQur'an oleh umat islam di dunia. Mempelajari dan memahami huruf hijaiyyah adalah langkah awal untuk membaca al-Qur'an (Gunawan, 2019). Oleh karena itu untuk meningkatkan dan mengembangkan pemahaman dalam membaca huruf hijaiyyah pada anak 
usia dini sangat penting dalam menggunakan metode atau media pembelajaran yang sesuai dengan strategi yang baik agar anak tertarik untuk mempelajari dan mengenal huruf hijaiyyah.

Kemampuan mengenal huruf merupakan potensi yang dimiliki anak usia dini untuk menyusun objek, bentuk, bilangan, suara ataupun simbol, yang di lakukan secara berulang dengan mengacu pada aturan tertentu. Agar dapat membuat anak lebih mengetahui secara bertahap terhadap penyusunan huruf hijaiyyah atau huruf yang lain dengan benar. Menurut Hamidah (Yuniansyah, 2020), untuk dapat mengetahui perkembangan anak saat menulis huruf hijaiyyah sebaiknya anak diberikan stimulasi menulis sehingga anak sudah terbiasa menggerakan pengelapan tangannya. Stimulasi menulis meliputi: 1) menebalkan bentuk; 2) mengikuti garis putus-putus atau titi-titik; 3) Menirukan bentuk; 4) Menulis sendiri aneka bentuk huruf hijaiyyah.

Menurut Mauliyah (2020), kemampuan mengenal huruf adalah kesanggupan melakukan sesuatu dengan mengenali tanda-tanda atau ciri- ciri dari tanda aksara dalam tata tulis yang merupakan anggota abjad yang melambangkan bunyi bahasa. Sedangkan menurut (Cania et al., 2020), dengan mengenalkan huruf kepada anak usia dini sebaiknya kenalkan dahulu huruf-huruf yang mudah bagi anak dan hindari huruf-huruf yang sulit. Untuk hurufhuruf yang sulit dapat di ajarkan setelah anak mampu merangkai kata. Hal yang sama juga disampaikan oleh Hidaya (2019) yang mengatakan bahwa pengenalan huruf biasanya tidak dilakukan secara langsung dengan menunjukkan huruf, melainkan melalui gambar-gambar tertentu, misalnya gambar jenis binatang atau gambar objek tertentu yang sudah dikenal anak. Hal yang sama juga disampaikan oleh mengatakan bahwa dalam mengenal huruf dengan menggunakan nama diri, nama benda di sekitarnya akan membantu anak untuk mengenal huruf-huruf, kata-kata dan suara, selain itu juga membantu anak untuk mulai belajar membaca dan menulis dengan cara menyambungkan antara bentuk huruf dengan bunyi huruf.

Menurut Rahayuningsih et al. (2016) mengatakan bahwa dalam mengenal huruf dengan menggunakan nama diri, nama benda di sekitarnya akan membantu anak untuk mengenal huruf-huruf, kata-kata dan suara, selain itu juga membantu anak untuk mulai belajar membaca dan menulis dengan cara menyambungkan antara bentuk huruf dengan bunyi huruf. Hal yang sama juga disampaikan oleh Purwanti (2017) yang menyatakan bahwa media gambar adalah setiap bentuk grafis statis maupun dinamis antara lain: foto, grafis, denah, ilustrasi (yang terdiri dari dua atau lebih gambar), dan juga animasi atau kartun. Tindakan membangun hubungan antara mental verbal dan mental pictorial adalah satu langkah penting dalam pemahaman konseptual. Materi yang disampingkan dengan multemidia yang terkontruksi dengan baik harusnya dapat menjadi lebih baik dalam menerima pesan dari pada hanya dengan kata-kata. Menurut Sari et al. (2020) terdapat kelebihan media gambar, yakni: a) sifatnya konkrit dan lebih realistis dalam memunculkan pokok masalah; b) dapat mengatasi batasan ruang dan waktu; dan c) dapat mengatasi keterbatasan pengamatan; d) memperjelas masalah bidang apa saja; dan e) harganya murah dan mudah didapat serta digunakan. Sedangkan kelemahan media gambar, yakni: a) hanya menampilkan presepsi indra mata ukurannya terbatas hanya dapat dilihat oleh sekelompok anak; b) gambar diinterprestasikan secara personal dan subjektif; dan c) gambar disajikan dalam ukuran yang sangat kecil, sehingga kurang efektif dalam pembelajaran.

Media kartu gambar dalam kegiatan proses belajar mengajar sangatlah penting sebagaimana dikemukakan oleh Kusumawati (2016) bahwa pemakaian media gambar pembelajaran dalam proses belajar mengajar dapat membangkitkan keinginan dan minat yang baru, membangkitkan motivasi dan rangsangan kegiatan belajar, dan bahkan membawa pengaruh-pengaruh psikologis terhadap anak. Sarudi (2018) mengemukakan bahwa beberapa fungsi dan kegunaan media kartu gambar pembelajaran, yakni: a) memberikan pengetahuan tentang tujuan belajar; b) motivasi anak; c) menyajikan informasi; d) merangsang diskusi; e) mengarahkan kegiatan anak; f) melaksanakan latihan dan ulangan g) 
menguatkan belajar dan h) dan memberikan pengalaman simulasi. Secara khusus media kartu gambar huruf hijaiyyah adalah alat peraga atau media yang digunakan untuk proses belajar mengajar anak usia dini.

\section{METODOLOGI}

Jenis penelitian ini adalah penelitian ekperimen semu (quasi experimental research), karena tidak semua variabel yang muncul dan kondisi eksperimen dapat diukur sepenuhnya. Tujuan penelitian ini adalah untuk menjelaskan pengembangan nilai agama tentang pengenalan huruf hijaiyyah melalui kartu gambar. Pendekatan yang digunakan dalam penelitian ini adalah pendekatan kuantitatif, karena semua gejala yang akan diteliti dapat diukur dan diubah ke dalam bentuk angka. Desain penelitian menggunakan desain eksperimen Pretest-Posttest, Non-Equivalent Control Group Design. Rancangan uji coba dapat dilihat pada tabel 2 .

Tabel 2. Desain Eksperimen Pretest-Posttest Non-Equivalent Control Group

\begin{tabular}{cccc}
\hline Group & Pretest & Perlakuan & Posttest \\
\hline $\mathrm{KK}$ & $\mathrm{O}_{1}$ & $\mathrm{Xb}$ & $\mathrm{O}_{2}$ \\
$\mathrm{KT}$ & $\mathrm{O}_{1}$ & $\mathrm{Xa}$ & $\mathrm{O}_{2}$ \\
\hline
\end{tabular}

Keterangan:

$\mathrm{KT}=$ Kelas treatment $(\mathrm{Xa})$

$\mathrm{KK}=$ Kelas kontrol $(\mathrm{Xb})$

$\mathrm{O} 1$ = Penilaian sebelum pembelajaran/pretest

$\mathrm{O} 2$ = Penilaian setelah pembelajaran/posttest

$\mathrm{Xa}=$ Pembelajaran menggunakan metode storytelling di kelas treatment

$\mathrm{Xb}=$ Pembelajaran menggunakan metode konvensional di kelas kontrol

Kelas treatment adalah kelas yang diberikan perlakuan dengan menggunakan media kartu gambar pada pembelajaran di kelas, sedangkan kelas kontrol adalah kelas dengan proses pembelajaran menggunakan pembejaran/ metode konvensional. Hal pertama yang dilakukan sebelum melakukan pembelajaran dengan menggunakan media kartu gambar di kelas, kelompok KT dan KK terlebih dahulu dilakukan penilaian (pretest) tentang pengenalan huruf hijaiyyah. Langkah berikutnya setelah pemberian perlakuan selesai pada kelas KK dan KT, dilaksanakan penilaian akhir (posttest) untuk mengetahui pengembangan nilai agama tentang pengenalan huruf hijaiyyah anak. Prosedur penelitian secara sederhana dapat dijelaskan pada gambar 1.

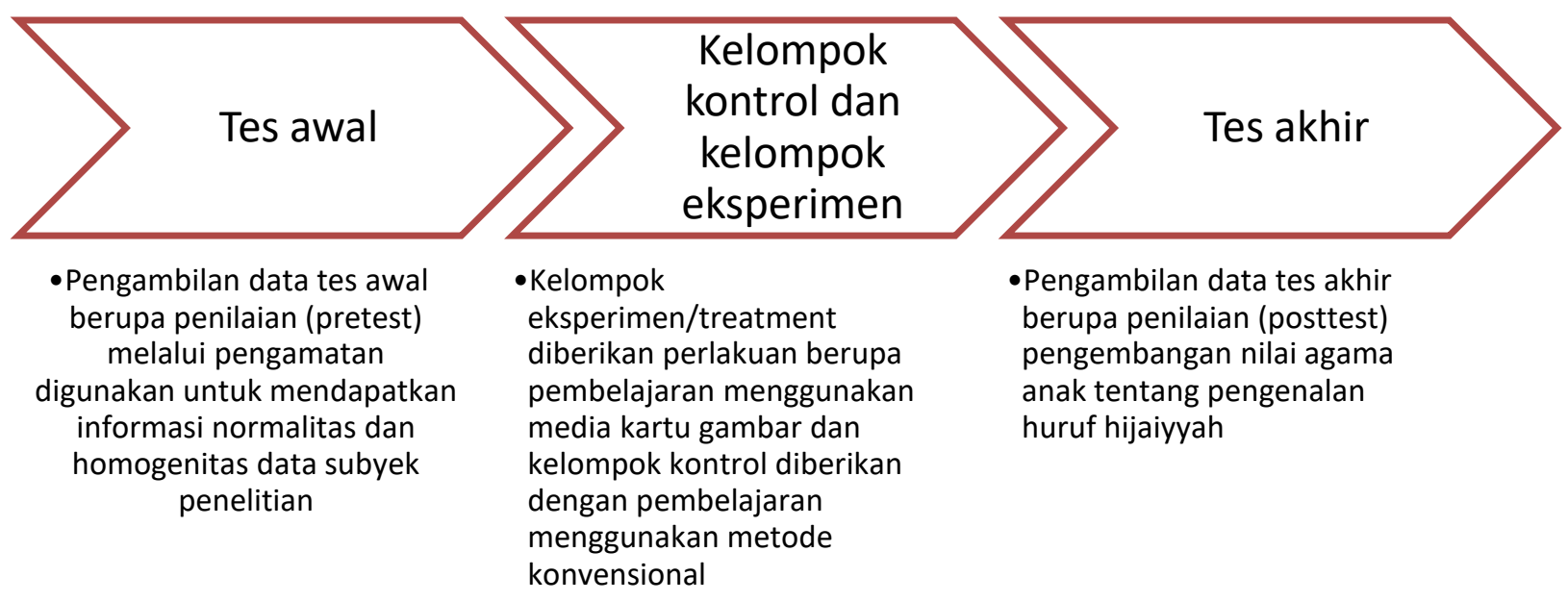

Gambar 1. Bagan desain penelitian 


\section{HASIL DAN PEMBAHASAN}

Anak-anak PAUD mengalami masalah pada berkurangnya kemampuan mengenal huruf hijaiyyah. Hal ini telah di observasi oleh peneliti sebelum melaksanakan penelitian. Untuk mengatasi hal tersebut, telah diberikan perlakukan dengan menggunakan media kartu gambar untuk mengembangkan dan merangsang anak untuk menganal huruf hijaiyyah. Penerapan media kartu huruf untuk meningkatkan kemampuan anak mengenal huruf hijaiyah dilakukan selama 4 minggu berturut-turut.

Hasil analisis berupa draft awal media kartu gambar untuk mengembangkan nilai agama pengenalan huruf Hijaiyyah untuk anak usia dini usia 5-6 tahun. Langkah uji coba terbatas ini sebagai sampel ada 15 anak. Tujuannya untuk mendapatkan nilai dari media kartu gambar dalam proses pembelajaran. Langkah uji efektivitas uji terbatas dari hasil penilaian sebagaimana terlihat pada tabel 1.

Tabel 1. Hasil Uji Terbatas Pengembangan Nilai Agama Pengenalan Huruf Hijayyah Melalui Media Kartu Gambar di TK Aisiyyah 2 Kota Palu

\begin{tabular}{lcc}
\hline \multirow{2}{*}{ Hasil } & \multicolumn{2}{c}{ Nilai Agama Pengenalan Huruf Hijaiyyah } \\
\cline { 2 - 3 } & Pretest & Postest \\
\hline Nilai Paling kecil & 17 & 25 \\
Nilai Paling Tinggi & 18,00 & 45,00 \\
Rerata & 23,2 & 35.867 \\
Standar Deviasi & 3,342 & 5,370 \\
Abs-gain & & 0,318 \\
\hline
\end{tabular}

Pada Tabel 1 nilai rerata nilai agama pengenalan huruf hijaiyyah pada uji coba terbatas dalam pelaksanaan pretest sebelum dilakukan proses pembelajaran sebesar 23.20 dan sesudah ada perlakuan menggunakan media kartu gambar sebesar 35,867. Sedangkan standar deviasi sebelum diterapkan media kartu gambar yakni 3.342 dan setelah diterapkan media kartu gambar 5.370 dan abs-gain adalah 0,318.

\section{Daya Guna Media Kartu Gambar}

Tehnik uji coba lapangan yang dilaksanakan pada anak-anak di TK Aisiyyah 2 kota Palu. Tehnik uji coba lapangan ada dua kelas dengan menerapkan eksperiment-control pretest posttest design. Anak usia dini yang digunakan dalam uji lapangan sebagai kelas eksperimen ada 15 anak di kelas B2 dan kelas B3 masing-masing 15 anak yang digunakan sebagai kelas control. Tehnik uji coba ini dilakukakn untuk mengetahui keterlaksanaan dan efektifitas media kartu gambar yang diterapkan bagi anak.

Tabel 2. Hasil Uji Lapangan Pemgembangan Nilai Agama Pengenalan Huruf Hijayyah Melalui Media Kartu Gambar di TK Aisiyyah 2 Kota Palu

\begin{tabular}{|c|c|c|c|}
\hline \multirow{2}{*}{ Data Statistik } & \multirow{2}{*}{ Kelas } & \multicolumn{2}{|c|}{ Nilai Agama Pengenalan Huruf Hijayyah } \\
\hline & & Pretest & Postest \\
\hline \multirow{2}{*}{ Minimum } & Kelas Eksperimen & 23,00 & 32,00 \\
\hline & Kelas Kontrol & 24,00 & 34,00 \\
\hline \multirow{2}{*}{ Maksimum } & Kelas Eksperimen & 45,00 & 55,00 \\
\hline & Kelas Kontrol & 41,00 & 34,00 \\
\hline \multirow{2}{*}{ Rata-rata } & Kelas Eksperimen & 34,1 & 40,50 \\
\hline & Kelas Kontrol & 29,14 & 37,00 \\
\hline \multirow{2}{*}{ Abs Gain } & Kelas Ekperimen & & \\
\hline & Kelas Kontrol & & \\
\hline
\end{tabular}


Berdasarkan tabel 2 dan rata-rata nilai, nilai agama pengenalan huruf hijayyah pada kelas ekperimen pada kegiatan pretest atau sebelum proses pembelajaran sebesar 34,10 dan setelah diberikan perlakuan dengan media kartu gambar sebesar 40.50. Pada Kelas Kontrol nilai agama pengenalan huruf hijayyah sebelum kegiatan pembelajaran sebesar 29.14 dan sesudah pembelajaran sebesar 37.00.Hasil ini membuktikan nilai agama pengenalan huruf hijayyah anak meningkat dengan menggunakan media kartu gambar. Peningkatan nilai agama anak pengenalan huruf hijayyah dibuktikan nilai abs gain sebesar 0.248 kelas eksperimen serta 0.224 kelas kontrol.

Hasil perhitungan uji manova didapatkan dari syarat yang digunakan dengan menggunkan statistika parametric yang mana nilai dari data yang didapatkan adalah normal dan homogen. Hasil dari uji Manova dapat dilihat pada tabel 3.

Tabel. 3 Hasil Uji Manova

Multivariate Tests ${ }^{a}$

\begin{tabular}{|ll|r|r|r|r|r|}
\hline Effect & & \multicolumn{1}{c|}{ Value } & \multicolumn{1}{c|}{ F } & Hypothesis df & Error df & Sig. \\
\hline Intercept & Pillai's Trace & .945 & $610.952^{\mathrm{b}}$ & 2.000 & 71.000 & .000 \\
& Wilks' Lambda & .055 & $610.952^{\mathrm{b}}$ & 2.000 & 71.000 & .000 \\
& Hotelling's Trace & 17.210 & $610.952^{\mathrm{b}}$ & 2.000 & 71.000 & .000 \\
& Roy's Largest & 17.210 & $610.952^{\mathrm{b}}$ & 2.000 & 71.000 & .000 \\
& Root & .087 & $3.376^{\mathrm{b}}$ & 2.000 & 71.000 & .040 \\
& Pillai's Trace & .913 & $3.376^{\mathrm{b}}$ & 2.000 & 71.000 & .040 \\
& Wilks' Lambda & .095 & $3.376^{\mathrm{b}}$ & 2.000 & 71.000 & .040 \\
& Hotelling's Trace & .095 & $3.376^{\mathrm{b}}$ & 2.000 & 71.000 & .040 \\
& Roy's Largest & & & & & \\
& Root & & &
\end{tabular}

a. Design: Intercept + KELOMPOK

b. Exact statistic

Berdasarkan tabel 3 didapatkan bahwa nilai signifikansi uji Hotelllings Trace kurang dari $(<0,05)$, maka dapat disimpulkan terdapat perbedaan peningkatan antara nilai agama pengenalan huruf hijayyah pada anak kelas eksperimen dan kelas kontrol. Kelas eksperimen yang menggunakan media kartu gambar memiliki peningkatan nilai agama pengenalan huruf hijayyah yang lebih tinggi dari pada kelas kontrol.

Pengambangan nilai agama pengenalan huruf Hijayyah anak melalui media kartu akan lebih baik jika dilakukan dan dikenalkan sejak dini baik di taman kanak-kanak maupun di Taman Pendidikan al-Qur'an, Lembaga Pendidikan, Pendidikan Orangtua dan dan dari lingkungan sekitar. Hal ini anak-anak dapat belajar seraya bermain karena bermain dapat merangsang anak dalam mengingat, menemukan sesuatu hal yang baru, dan anak mampu membangun suatu konsep serta dapat bereksplorasi, sehingga bermain sangat penting bagi anak usia dini. Salah satunya pengenalan huruf hijayyah menggunakan media kartu gambar. Dengan demikian anak dapat mudah mengenal dan membedakan pengucapan huruf hijayyah dan mengenal huruf Hijayyah. Media kartu merupakan salah satu media yang dianggap efektif untuk meningkatkan kecerdasan anak usia dini (Purwanti, 2017). Selanjutnya Sari et al. (2020) menyatakan bahwa adanya peningkatan membaca anak dengan menggunakan media kartu gambar pada anak PAUD. Kemudian Bastian (2021) dalam penelitiannya menyimpulkan bahwa melalui media kartu dapat meningkatkan mengenal huruf hijayyah anak Usia Usia 5-6 tahun. Fauziddin \& Fikriya (2020) menggunakan permainan kartu huruf hijaiyah yang dilengkapi kosakata bahasa Arab dalam meningkatkan kemampuan mengenal bahasa Arab pada anak usia dini.

Kemampuan mengenal huruf adalah kesanggupan melakukan sesuatu dengan mengenali ciri-ciri dari tanda aksara dari tata tulis yang merupakan anggota abjad yang melambangkan bunyi bahasa (Bastian, 2021). Hal tersebut dibuktikan dengan penelitian yang dilakukan oleh Bante \& Umrah (2018) menemukan bahwa dengan menggunakan media kartu 
hijaiyah, aktivitas belajar anak (sikap dan keterampilan) anak meningkat selama proses pembelajaran. Hal ini stimulasi yang diberikan pada anak untuk meningkatkan kemampuan mengenal huruf hijaiyyah melalui media kartu gambar sangat efektif untuk dikembangkan.

\section{SIMPULAN}

Kemampuan mengenal huruf hijaiyah pada anak dapat ditingkatkan dan kembangkan dengan menggunakan media kartu gambar. Peningkatan dalam penerapan media kartu gambar dapat berkembang sesuai harapan setelah dilakukan pretest dan posttest. Hal ini dapat dibuktikan dengan adanya peningkatan anak dalam mengenal huruf hijaiyyah setelah menggunakan media kartu gambar yakni pada pretest dan postest diperoleh presentasi nilai yang meningkat dan signifikan. Hal ini menunjukkan bahwa media kartu gambar sangat efektif digunakan dalam mengembangkan nilai agama mengenal huruf hijaiyyah pada anak usia dini.

\section{UCAPAN TERIMA KASIH}

Peneliti mengucapkan terimakasih kepada Dekan Fakultas Keguruan dan Ilmu Pendidikan yang telah memberikan dana Hibah Penelitian, Kepala sekolah, guru dan staf serta semua pihak yang sudah berpartisipasi dan berkontribusi dalam penelitian ini. Semoga mendapatkan keberkahan dan menjadi amal jariyah.

\section{DAFTAR PUSTAKA}

Ananda, R. (2017). Implementasi Nilai-nilai Moral dan Agama pada Anak Usia Dini. Jurnal Obsesi : Jurnal Pendidikan Anak Usia Dini, 1(1), 19-31. https://doi.org/10.31004/obsesi.v1i1.28

Anggraini, W., \& Syafril, S. (2018). Pengembangan Nilai-Nilai Moral dan Agama pada Anak Usia Dini. Jurnal Pendidikan Anak Usia Dini, 3(1). https://doi.org/10.13140/RG.2.2.22657.10085 https://doi.org/10.31219/osf.io/dbnya

Ardiansari, B. F., \& Dimyati, D. (2021). Identifikasi Nilai Agama Islam pada Anak Usia Dini. Jurnal Obsesi : Jurnal Pendidikan Anak Usia Dini, 6(1), 420-429. https://doi.org/10.31004/obsesi.v6i1.926

Bante, M., \& Umrah, S. (2018). Pemahaman Huruf Hijaiyah dengan Menggunakan Media Kartu. 4(1), 11-14. https://doi.org/10.32489/alfikr.v4i1.36

Bastian, A. (2022). Upaya Meningkatkan Kemampuan Mengenal Huruf Hijaiyah melalui Media Gambar. 6(3), 1303-1311. https://doi.org/10.31004/obsesi.v6i3.1772

Cania, S., Novianti, R., \& Chairilsyah, D. (2020). Aulad: Journal on Early Childhood Pengaruh Media Glowing City terhadap Kemampuan Mengenal Bentuk Geometri pada Anak Usia Dini. 3(1), 53-60. https://doi.org/10.31004/aulad.v3i1.54

Fauziddin, M., \& Fikriya, M. (2020). Mengenal Kosakata Bahasa Arab melalui Permainan Kartu Huruf Hijaiyah yang Dilengkapi Kosakata. 1(1), 46-54. https://doi.org/10.37985/joe.v1i1.19

Gunawan, W. (2019). Pengembangan Aplikasi Berbasis Android Untuk Pengenalan Huruf Hijaiyah. 6(1), 69-76. https://doi.org/10.31311/ji.v6i1.5373

Haanuddin, S. M. (2017). Pembelajaran huruf Hijaiyah bagi anak usia dini. Proceedings of The 2nd Annual Conference on Islamic Early Childhood Education, 175-188.

Hakim, L., \& Dalli, C. (2016). 'To be professional is a never-ending journey': Indonesian early childhood practitioners' views about the attitudes and behaviours of a professional teacher. Early Years, 5146(December), 1-14. https://doi.org/10.1080/09575146.2016.1256275

Hidaya, A. Al. (2019). Pembelajaran Huruf Hijaiyyah Pada Sentra Agama Di Taman Kanak-Kanak Tunas 1001 Takengon Aceh Tengah.

Inawati, A. (2017). Strategi Pengembangan Moral dan Nilai Agama Untuk Anak Usia Dini Asti Inawati. Al-Athfal Jurnal Pendidikan Anak, 3(1), 51-64.

Kusumawati, K., Doyin, M., Bahasa, J., Bahasa, F., \& Semarang, U. N. (2016). Jurnal Pendidikan Bahasa dan Sastra Indonesia. 5(1).

Mauliyah, A. (2020). Media Kartu Huruf Dengan Metode Kupas Karangtanjung Candi Sidoarjo. 1.

Purwanti, T. (2017). Deskripsi Menggunakan Media Kartu Gambar Pada Siswa Kelas IV SD Negeri 2 Geneng Jepara. 5, 100-105. https://doi.org/10.30659/j.5.2.100-105 
Rahayuningsih, S. S., Soesilo, T. D., \& Kurniawan, M. (2016). Peningkatan Kemampuan Mengenal Huruf Pada Anak Usia 5-6 Tahun Melalui Metode Bermain Dengan Media Kotak Pintar. 1118. https://doi.org/10.24246/j.js.2019.v9.i1.p11-18

Sari, B. F., Sari, S. E., Chedeng, S., \& Wahyuni, I. W. (2020). Upaya Meningkatkan Kemampuan Membaca Melalui Media Kartu Gambar Di PAUD Ar-Rahma. 3, 121-131. https://doi.org/10.30998/jurnalpkm.v3i2.4335

Sarudi, W. (2018). Penggunaan Media Kartu Gambar Berseri untuk Meningkatkan Kemampuan Menulis Cerpen Siswa Kelas IX G SMPN 3 Wates Kediri. 1-10. https://doi.org/10.21776/ub.hastawiyata.2018.001.01.06

Wang, J., Hilliard, L. J., Hershberg, R. M., Bowers, E. P., Chase, P. A., Champine, R. B., Buckingham, M. H., Braun, D. A., Gelgoot, E. S., \& Lerner, R. M. (2015). Character in childhood and early adolescence: models and measurement. https://doi.org/10.1080/03057240.2015.1040381

Yuniansyah, A. S. (2017). Pengembangan Multimedia Pembelajaran Pengenalan Huruf Hijaiyah Menggunakan Metode 4-D. 45-56. https://doi.org/10.30812/matrik.v17i2.77

Zahrotun, L. (2015). Media Pembelajaran Pengenalan Huruf Hijaiyah Untuk Anak Usia Dini 2-3 Tahun. Telematika, 12(2), 75-81. https://doi.org/10.31315/telematika.v12i2.1405 